\title{
Adsorption Characteristics and Behaviors of Natural Red Clay for Removal of BY28 from Aqueous Solutions
}

\author{
Omer Lacin, Ali Haghighatnia, Fatih Demir, Fatih Sevim \\ University of Ataturk, Department of Chemical Engineering, Erzurum, Turkey
}

\begin{abstract}
The present study deals with the analysis and adsorption of Basic Yellow 28 (BY28) onto low-cost natural red clay (NRC). Adsorbent characterized by XRD, SEM, TG/DTA, BET and BJH. The effect of the contact time, the temperature, the initial concentration, the $\mathrm{pH}$ and the adsorbent mass and on adsorption process were investigated using by batch adsorption technique and then the adsorption isotherm, kinetics, thermodynamics and equilibrium studies were performed. The pH effect on the removal of BY28 efficiency was not important. It was found that the isotherm model best suited to the equilibrium data obtained from the adsorption of BY28 on NRC was the pseudo-second order. It was found that the kinetic model best suited to the data obtained from the adsorption of BY28 on NRC was the Langmuir model. The maximum monolayer adsorption capacity was $370 \mathrm{mg}$. g-1. In the thermodynamic studies, it can be said that the adsorption of BY28 onto NRC takes place spontaneously, physically and endothermic ally. Finally, the use of NRC shows a greater potential for the removal of cationic dyes, as no costly equipment is required.
\end{abstract}

Keywords: Adsorption, Characterization, Clay, Isotherm, Kinetic, Basic Yellow 28

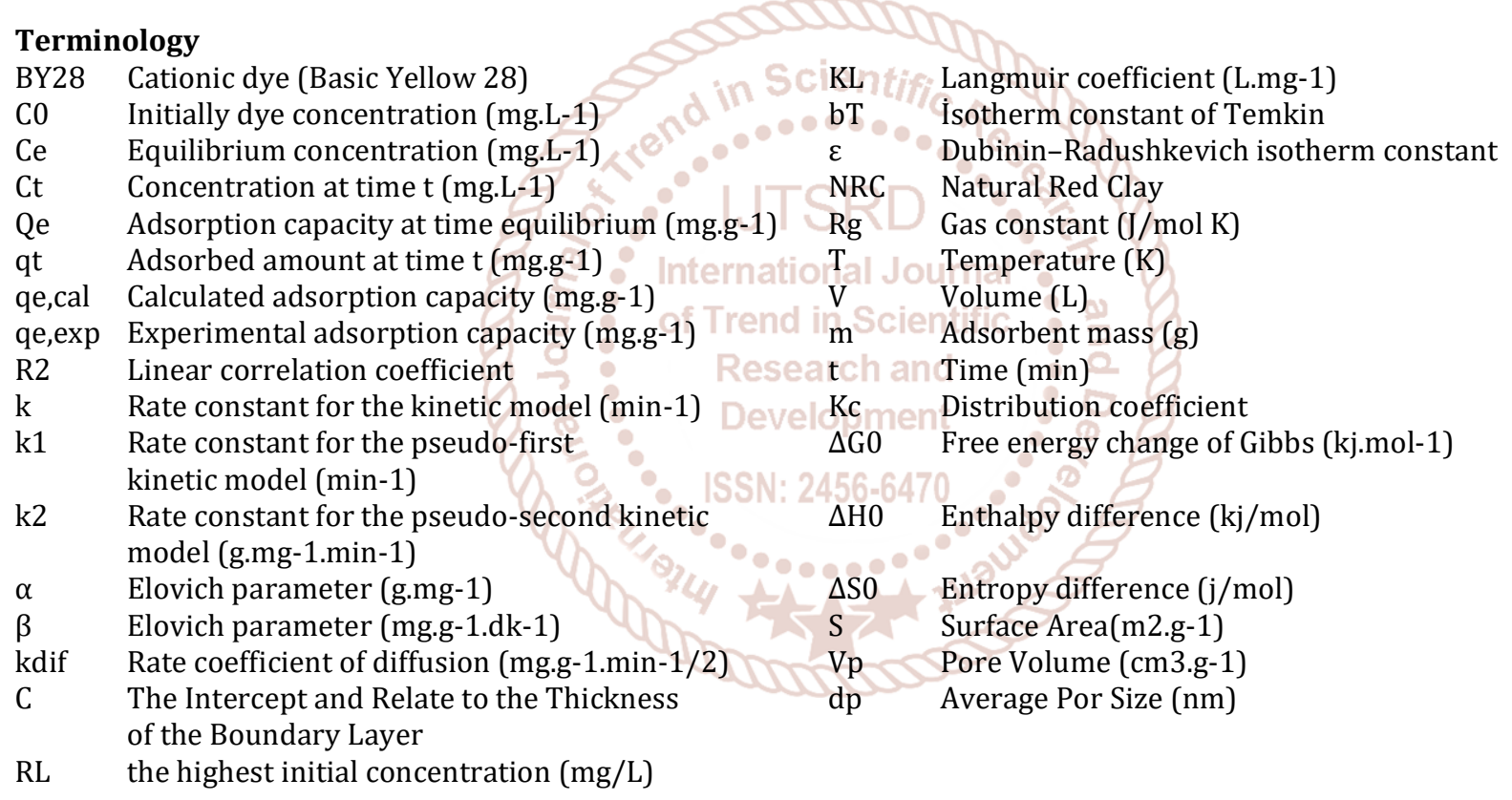

\section{INTRODUCTION}

As a result of the rapid increase in the use of dyestuff in most industrial plants, it has caused a significant increase in environmental pollution. Dyestuffs are greatly used for tanning, dyeing, textile, cosmetics, printing, food, etc. in industries [1]. Most of these dyes are harmfull to human health and the aquatic ecosystems. One of the biggest problems in the industry is the discharge to receiver medium of dyestuffs in wastewater ${ }^{[2]}$.

The probable techniques of removal of dyestuffs from wastewater include adsorption, coagulation, membran filtration, precipitation, ion exchange, biological processes, chemical oxidation, etc. Between all these techniques, adsorption is an effective and cheap process compared to other expensive techniques. Therefore, recently many cheap adsorbents were investigated in the removal of dyestuffs. In the literature, many different adsorbents have been used to remove dyestuffs in aqueous solutions [3-12].
For all that, it should be beared in mind that the most commonly used adsorbent is activated carbon. Because it has properties such as porous structure, high adsorption capacity and large surface area [13,14]. But, there were expensive absorbent the materials and it became more and more important to take into account the cost of treating contaminated water $[15,16]$.

Natural clays are often used in adsorption processes because they are cheap, abundant and eco-friendly [17-20].

Therefore, a low cost new adsorbent has been proposed to remove Basic Yellow 28 (BY28) from wastewater in this study.

The major purpose present study was to examine the adsorption of BY28 (Maxilon Golden Yellow GL) taken from 
Mem Textile Plant in Kahramanmaras-Turkey, on natural red clay (NRC), a clay with majorly smectite taken from the Oltu/Erzurum region in Turkey.

BY28 is a cationic substance because it forms a positively charged ion when dissolved in aqueous solutions. Table 1 shows some properties of NRC used as adsorbent. NRC; was analyzed by techniques such as XRD, SEM, DTA-TGA, BET and $\mathrm{BJH}$.
The effect of the contact time, the initial concentration, the temperature, the $\mathrm{pH}$ and the adsorbent mass on adsorption process were investigated and the adsorption kinetics, thermodynamics and equilibrium studies were achieved by batch adsorption technique. Besides, adsorption isotherm model of this study are compared with various adsorption isotherm models found in the literature.

Table 1 Properties of BY28 dye and NRC

\begin{tabular}{|c|c|c|c|c|c|}
\hline Dye & Max. Golden Yellow GL 200\% & Content & Quantity \% & Content & Quantity \% \\
\hline Color index & Basic Yellow 28 & Clay & 69 & Smectite & 45 \\
\hline Stability of pH & $3-10$ & Calcite & 17 & chlorite & 27 \\
\hline K values & 3.0 & feldspar & 8 & Kaoline & 18 \\
\hline F values & 0.46 & Quartz & 6 & illite & 10 \\
\hline$\lambda$ max & 437 & & & & \\
\hline \multirow{2}{*}{ Solubility } & $40 \mathrm{~g} . \mathrm{L}^{-1}(30 \circ \mathrm{C})$ & & & & \\
& $\begin{array}{l}60 \mathrm{~g} \cdot \mathrm{L}^{-1}(60 \circ \mathrm{C}) \\
80 \mathrm{~g} \cdot \mathrm{L}^{-1}(90 \circ \mathrm{C})\end{array}$ & & & & \\
\hline Shape Powder & liquid 200\%, powder 200\%, particular 200\% & & & & \\
\hline
\end{tabular}

\section{EXPERIMENTAL}

\subsection{Materials}

In present study, the cationic textile dye, BY28, were supplied by Mem Textile Plant in Kahramanmaras-Turkey. Open structure of chemical formula of BY28 The chemical structures of dyes are given in Fig. 1 and properties are given Table 1.

NRC (mineral from Oltu/Erzurum region) was used as adsorbents. The NRC was sieved through -200 mesh sieved, washed with distilled water and then dried overnight at $105^{\circ} \mathrm{C}$. Some information about NRC are given in Table 1-2. All the chemicals used were of analytical purity.

Table 2 Quantitative analysis of NRC sample [21].

\begin{tabular}{|c|c|}
\hline Content & Quantity \% \\
\hline $\mathrm{Na}_{2} \mathrm{O}$ & 0,20 \\
\hline $\mathrm{MgO}$ & 8,10 \\
\hline $\mathrm{Al}_{2} \mathrm{O}_{3}$ & 14,44 \\
\hline $\mathrm{SiO}_{2}$ & 41,48 \\
\hline $\mathrm{K}_{2} \mathrm{O}$ & 1,23 \\
\hline $\mathrm{CaO}$ & 11,14 \\
\hline $\mathrm{TiO}_{2}$ & 0,53 \\
\hline $\mathrm{Fe}_{2} \mathrm{O}_{3}$ & 9,88 \\
\hline $\mathrm{LOI}$ & 13 \\
\hline
\end{tabular}

\subsection{Adsorption Studies}

All experiments were performed by the batch adsorption technique. For adsorption researches, the initial concentration, the contact time, the temperature, the $\mathrm{pH}$ and the adsorbent mass were as 1-180 min, 50-300 mg/L, 3-10, $0.5-10 \mathrm{~g} / \mathrm{L}$ and $25-40{ }^{\circ} \mathrm{C}$, respectively. The values selected for these parameters are given in Table 3.

\section{Basic Yellow 28 (BY28)}

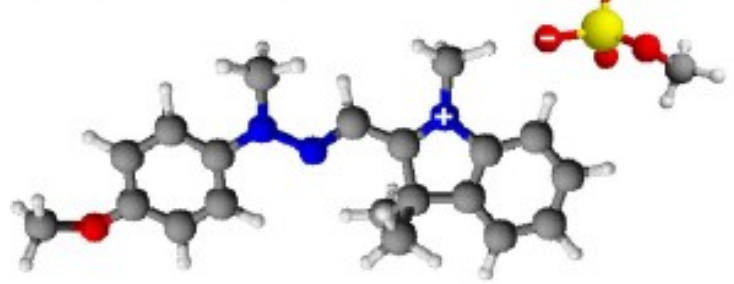

Fig.1. Open structure of BY28 ( carbon atoms in black, hydrogen atoms in white, oxygen atoms in red, nitrogen atoms in blue and sulfur atoms in yellow are shown).
Table 3 Experimental parameters and values in BY28 adsorption

\begin{tabular}{|c|c|}
\hline Parameter & Values \\
\hline $\begin{array}{c}\text { Contact time }(\mathrm{dk}) \\
\text { (mg/L) }\end{array}$ & $1-5-10-30-60 *-120-180$ \\
\hline temperature $\left({ }^{\circ} \mathrm{C}\right)$ & $50-100-200 *-300$ \\
\hline Solution pH & $25^{*}-30-35-40$ \\
\hline Adsorbent mass & $3-4 *-7-9-10$ \\
\hline cientifi (g/L) & $0.5-1.0-1.5-2.0 *-2.5-3.0-4.0-$ \\
\hline
\end{tabular}

* Constant selected values when analyzing the effect of parameters
The $\mathrm{pH}$ values with a digital $\mathrm{pH}$-meter (model Thermo Orion 3 Star pHmeter) were adjusted by adding a few drops $0.1 \mathrm{M}$ $\mathrm{NaOH}$ or $0.1 \mathrm{M} \mathrm{HCl}$ solutions. Adsorption experiments were carried out at a constant stirring speed of $225 \mathrm{rpm}$ in a temperature-controlled shaker (Edmund Bühler Gmbh KS15)., The resulting mixture was centrifuged (model Nuve NF 1215 ) at $5000 \mathrm{rpm}$ for $15 \mathrm{~min}$. BY28 Concentration was found by a Mapada UV spectrophotometer by using calibration curve at the maximum wavelength corresponding to BY28 (437 nm).

The percent removal of BY28 was found using Eq. (1):

$$
\text { BY28 Removal } \%=\frac{\left(C_{0}-C_{\mathrm{t}}\right)}{C_{\mathrm{o}}} \times 100
$$

where $\mathrm{C}_{0} \quad\left(\mathrm{mg} \cdot \mathrm{L}^{-1}\right)$ and $\mathrm{C}_{\mathrm{t}} \quad\left(\mathrm{mg} . \mathrm{L}^{-1}\right)$ are the BY28 concentrations at the initially and time $t$, respectively. Adsorption capacity at equilibrium, $\mathrm{q}_{\mathrm{e}}\left(\mathrm{mg}^{\mathrm{g}} \mathrm{g}^{-1}\right)$ was fond from the initial $\left(\mathrm{C}_{0}\right)$ and equilibrium $\left(\mathrm{C}_{\mathrm{e}}\right)$ By28 concentrations (mg.L $\mathrm{L}^{-1}$ ) in the solution Eq. (2):

$$
q_{e}=\left(c_{0}-c_{e}\right) \frac{V}{m}
$$

where, $\mathrm{V}(\mathrm{L})$ is the solution volume and $\mathrm{m}(\mathrm{g})$ is the NRC mass.

\subsection{Characterizations}

A specimen was characterized by X-ray diffraction using Rigaku 2200D/Max, X-ray diffractometer, the radiation used was $\mathrm{Cu} \mathrm{K} \alpha(\lambda=1.5405 \AA)$ radiation in the $2 \theta$ range $0-35^{\circ}$ was used. A ZEISS SIGMA 300 Scanning Electron Microscopy (SEM) was used to characterize the NRC surface morphology 
in which the sample was prepared and deposited on the support after mineralization with gold.

Termogravimetry/Differential Thermal Analysis (TG/DTA) was used on NETZSCH STA 409 PC Luxx with high-resolution. Under atmospheric pressure, the NRC was analyzed from 20 to $1000{ }^{\circ} \mathrm{C}$ at $10{ }^{\circ} \mathrm{C} \mathrm{min}-1$ heating rates.

With Micromeritics 3Flex device, surface area analysis with Brunauer-Emmett-Teller (BET) and pore size-volume analysis with Barrett-Joyner-Halenda (BJH) were carried out.

\subsection{Adsorpiton Isotherm, Kinetics and Thermodynamic Equations}

The Langmuir isotherm describes the formation of a monolayer adsorbate on sites in the adsorbent quantitatively, and then there are no multiple layers after this layer. Thereby, it is the most important equations that give information about the adsorbed molecules and their distribution between solid and liquid phase at equilibrium. The parameters in isotherm equations give informations about surface properties, adsorption mechanisms and affinities of the adsorbent. The Langmuir isotherm essential characteristics of can be expressed with a dimensionless equilibrium parameter $\left(\mathrm{R}_{\mathrm{L}}\right)$. The $\mathrm{R}_{\mathrm{L}}$ values indicate the type of the isotherm (unfavorable $\left(R_{L}>1\right)$ ), linear $\left(R_{L}=1\right)$, favorable $\left(0<R_{L}<1\right)$ or irreversible $\left.\left(R_{L}=0\right)\right)$. The Freundlich isotherm is generally used to define adsorption properties for the heterogeneous surface and assumes that adsorption occurs in regions with different adsorption energy. If $n$ value is bbetween 1 and 10 , the adsorbent is suitable for adsorption.

The Temkin isotherm is generally applied to explain adsorbate- adsorbent interactions. It is characterized by a homogenous distribution of binding energies.

The Dubinin Radushkevich isotherm is mostly tested to explain the adsorption mechanism and nature (especially on porous adsorbents) with a Gaussian energy distribution onto a heterogeneous surface.

It is also very important to examine the kinetics to determine what adsorption mechanism control. So, several kinetic models have been reported in the literature. In this study, Elovich, Pseudo-First-Order, Pseudo-Second-Order and intra-particle diffusion were tested. Therefore, experimental adsorption isotherms and kinetics are compared with the isotherms and kinetics given in Table 4 and Table 5, respectively.

Table 4 Isotherms models commonly used in aqueous solutions.

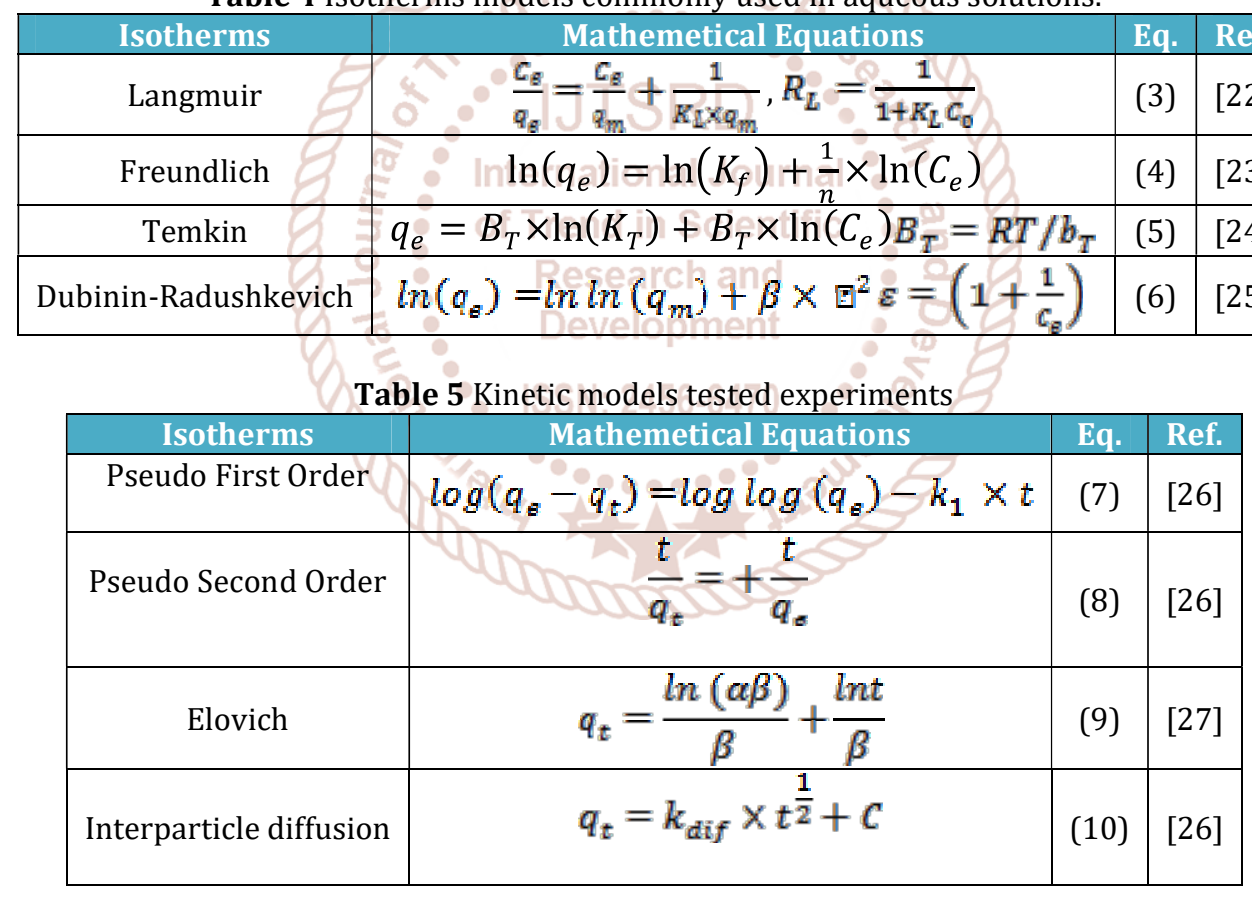

In thermodynamic investigations, it should first be decided whether the adsorption process is spontaneous or not. The Gibbs free energy change $\left(\Delta \mathrm{G}^{0}\right)$ is an indication of spontaneity and therefore is an important criterion. In order to determine the $\Delta \mathrm{G}^{0}$ of the process, enthalpy change $\left(\Delta \mathrm{H}^{0}\right)$ and entropy change $\left(\Delta \mathrm{S}^{0}\right)$ should be founded. At a given temperature, if $\Delta \mathrm{G}^{0}$ is a negative quantity, reactions occur spontaneously. Additionally, $\Delta \mathrm{G}^{0}$ can also be found with Van't Hoff equation:

$$
\Delta G^{\circ}=-R_{g} T \times \ln \left(K_{c}\right)
$$

$K_{c}$ is adsorption distribution coefficient defined as:

$$
K_{e}=\frac{q_{e}}{c_{e}}
$$

$$
\ln \left(K_{c)}=\left(\Delta S^{\circ} / R_{g}\right)-\left(\Delta H^{\circ} / R_{g} T\right)\right.
$$

\section{RESULTS AND DISCUSSION}

\subsection{NRC Characterization}

X-ray diffraction (XRD) pattern of NRC is exhibited in Fig. 2. XRD pattern of NRC were obtained in three ways: drying at room temperature, solvation with ethylene glycol and heating at $550^{\circ} \mathrm{C}$ for $2 \mathrm{~h}$. Clay minerals were described in the position of the (001) basal reflections series in the three (XRD) patterns [28]. Semiquantitative estimates of the basal reflection peak areas for the major clay mineral groups (smectite: $2 \theta=5.3(17 \AA)$, illite: $2 \theta=8.9(10 \AA)$, and kaolinite/chlorite: $2 \theta=12.6(7 \AA)$ have been reported [29].

By combining Eq.11 -12, $\Delta \mathrm{G}^{0}$ is calculated as follows: 


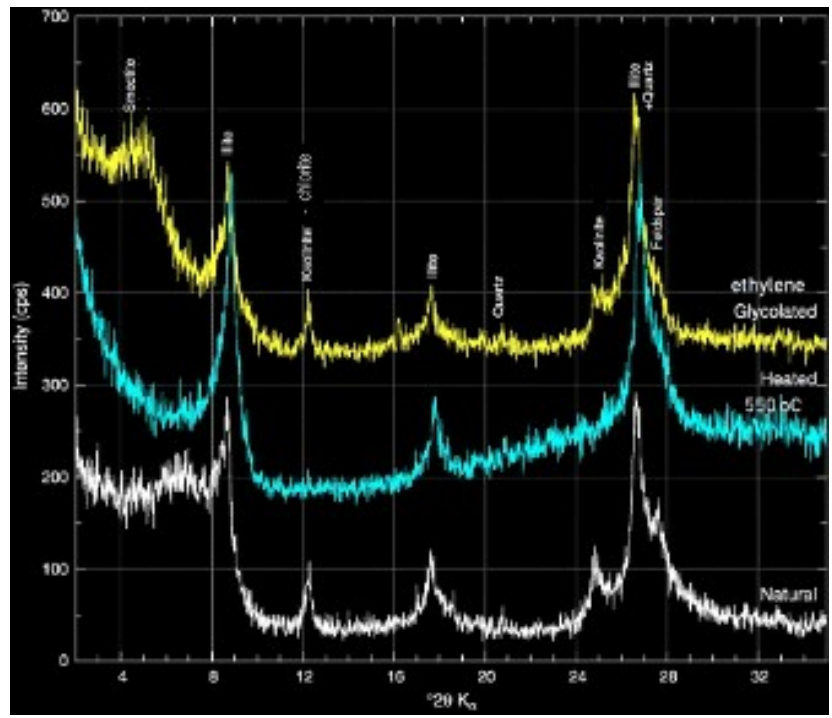

Fig.2. Typical XRD patterns of NRC

When Fig. 2 is examined, it can be seen that similar characteristic peaks are formed. In Fig. 3 a-d NRC SEM Micrograph before and after adsorption, respectively is showen.
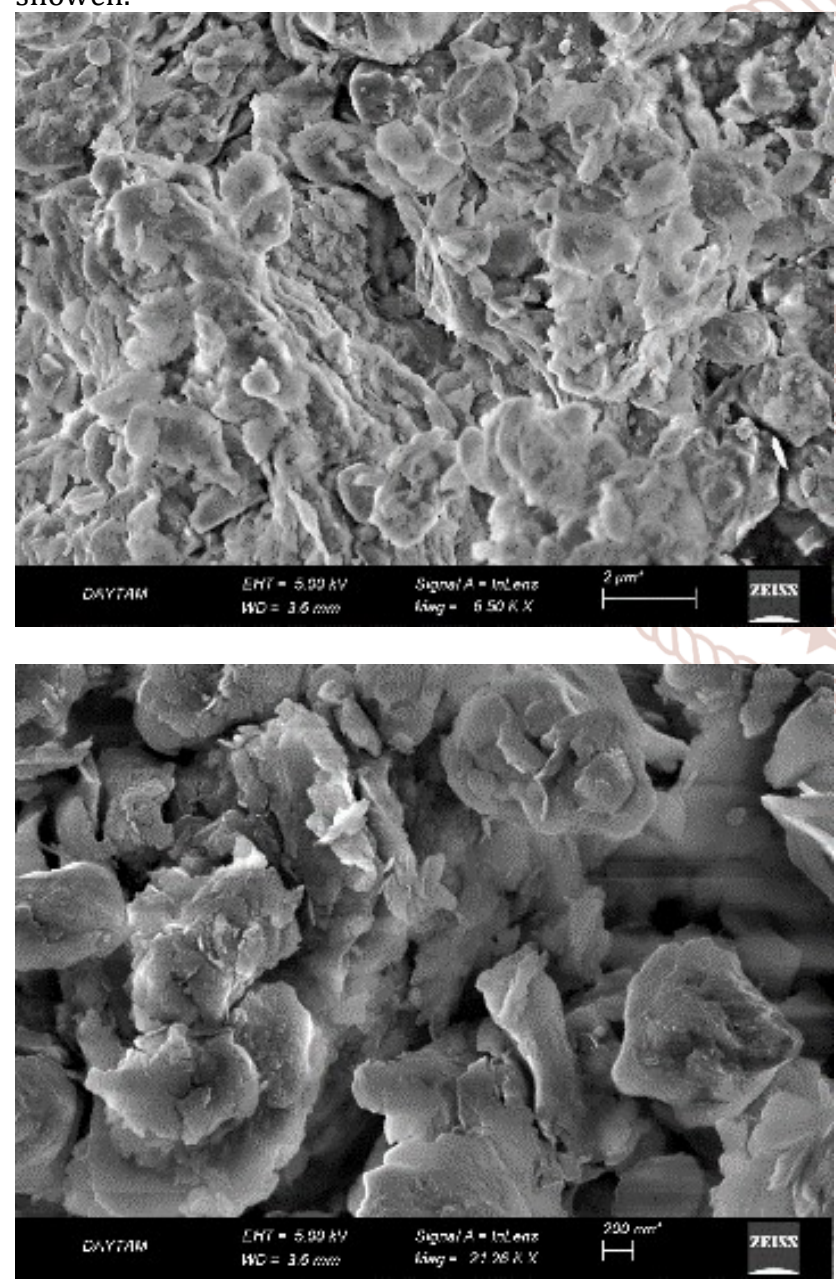
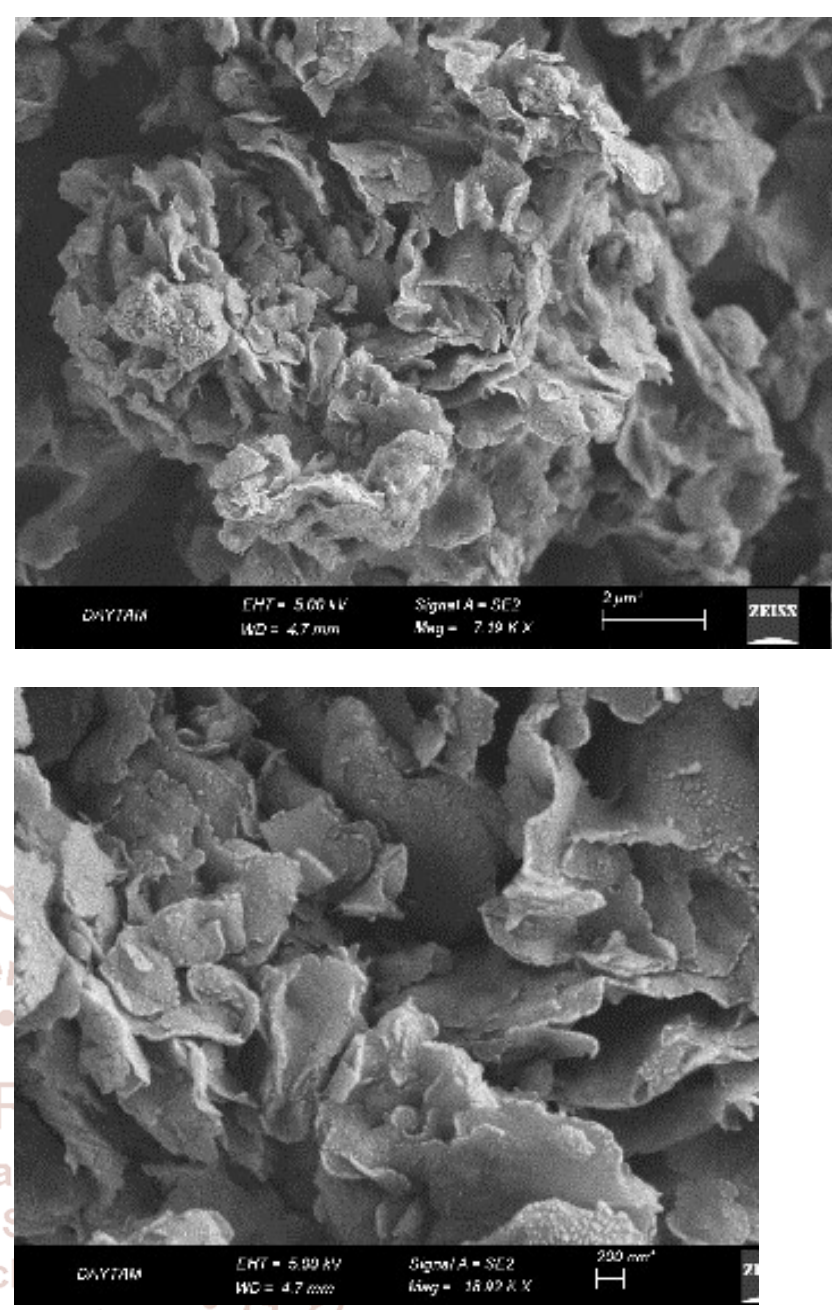

Fig.3. a-b and c-d SEM micrograph of NRC before and after adsorption, respectively.

It can be seen from Fig. 3. a-b that the adsorbent has a rough and heterogeneous porous structure. It can also be seen from Fig. 3. c-d that the dye molecules are more likely to be adsorbed on to the surface of the adsorbent.

In the DTA-TG analyzes of NRC (Fig. 4.); They reported that they lost free water in clay structure at $80-100{ }^{\circ} \mathrm{C}$, lost crystal water between clay layers at $100-300{ }^{\circ} \mathrm{C}$ and that dehydroxylation took place due to endothermic reactions above $300{ }^{\circ} \mathrm{C}$, thus removing structural water. It is also expressed that from curve in Fig. 4. is showed dehydroxylation peaks in illite mineral at $548{ }^{\circ} \mathrm{C}$ and montmorollite mineral at $715^{\circ} \mathrm{C}$.

The NRC surface analysis results are given in Fig. 5 and Table 6.

Table 6 The NRC Surface Analysis Results.

\begin{tabular}{|c|c|c|}
\hline $\begin{array}{c}\text { Surface Area(S, } \\
\left.\mathbf{m}^{2} \cdot \mathrm{g}^{-1}\right)\end{array}$ & $\begin{array}{c}\text { Pore Volume }\left(\mathrm{V}_{\mathrm{p}},\right. \\
\left.\mathrm{cm}^{3} \cdot \mathrm{g}^{-1}\right)\end{array}$ & $\begin{array}{c}\text { Average Por Size } \\
\left(\mathrm{d}_{\mathrm{p}} \mathbf{n m}\right)\end{array}$ \\
\hline $\mathbf{4 1 , 8 7}$ & 0,046 & 4,37 \\
\hline
\end{tabular}




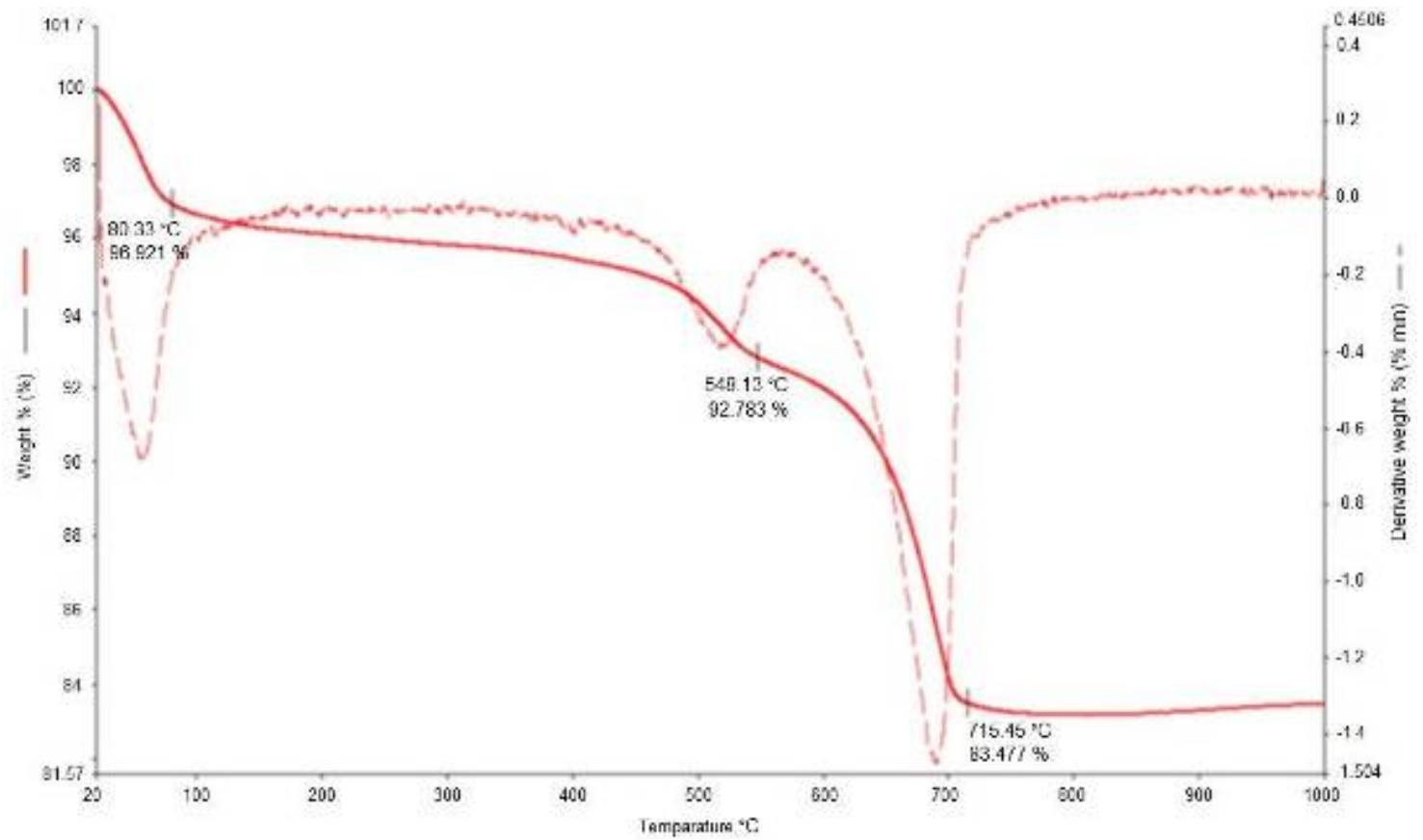

Fig.4. DTA-TG curves for NRC
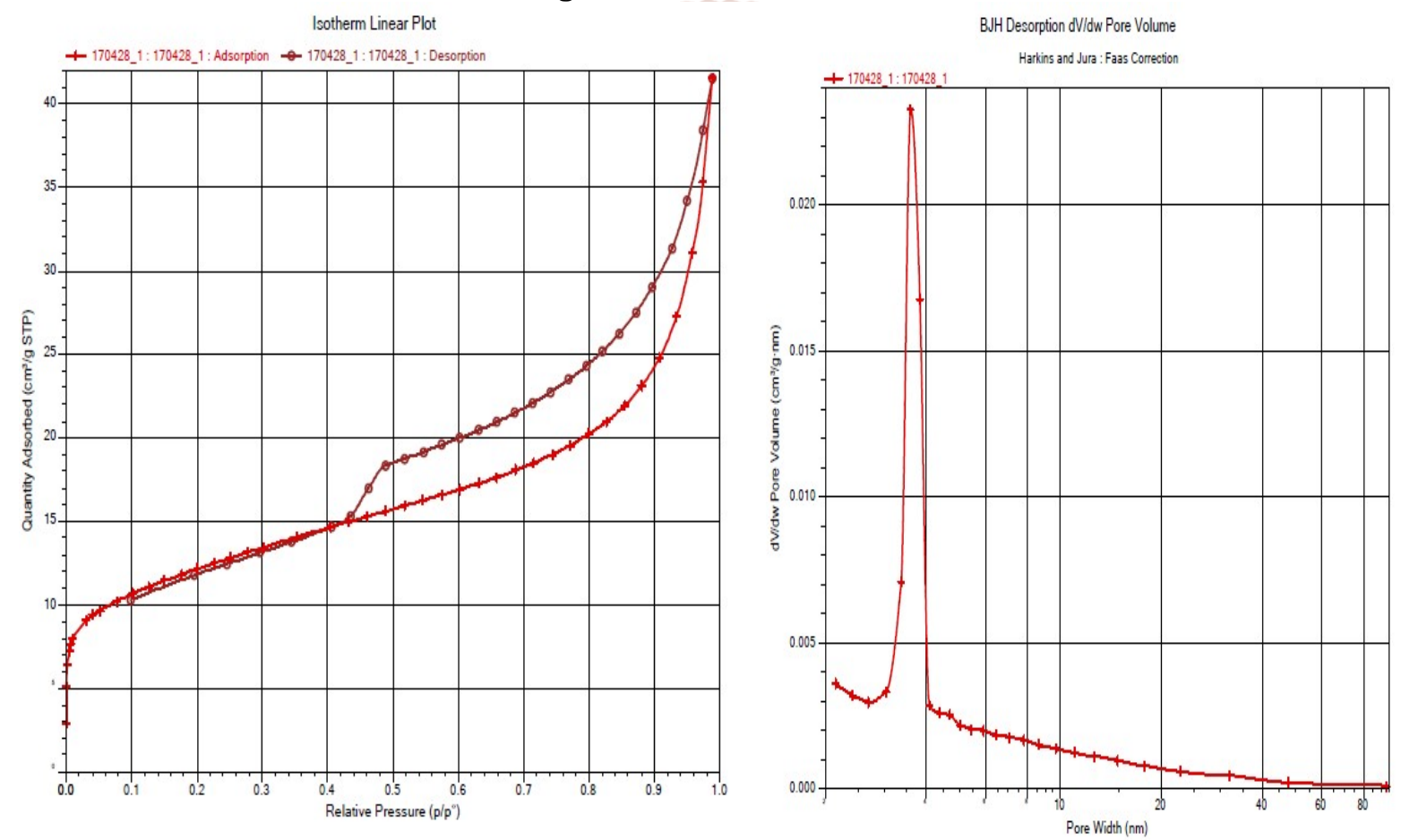

Fig.5. Adsorption isotherm and pore size distribution plot of nitrogen at $77 \mathrm{~K}$ for NRC

\subsection{Effect of initial concentration and contact time on the adsorption capacity}

The change in the adsorption capacity $\left(\mathrm{q}_{\mathrm{t}}\right)$ with contact time given different initial concentrations (50 - $300 \mathrm{mg} . \mathrm{L}^{-1}$ ) is given in Fig. 6 . The adsorption rate was high at the beginning of the process and then the rate of adsorption was becoming smaller and become stagnanted with the increase in contact time and eventually the equilibrium was reached. The BY28 amount adsorbed per NRC unit mass at equilibrium increased with increase in initial concentrations. Increasing the initial dye concentration means that the adsorbent is quickly saturated. Because of this, adsorption occurs slowly in the pores through diffusion of the intraparticles. The steric repulsion between the solute molecules can also alow down the adsorption process [30,31].
As shown in Fig. 6., the equilibrium time for BY28 adsorption on NRC is approximately $60 \mathrm{~min}$, and this time was used in all subsequent experiments.

\section{3. $\quad \mathrm{pH}$ effect on the adsorption capacity}

The adsorption of BY28 dyes onto NRC was determined by changing the $\mathrm{pH}$ in the range of 3.0-10.0 and given in Fig. 7. This figure shows that the adsorption process is independent of $\mathrm{pH}$. The similar phenomenon has been reported by Turabik and Eren -Afsin [32,33]. In this case, the adsorption mechanism take places partialy depending on the noncolumbic interactions by ion exchange in a neutralized site with an adsorbed cation and partially ion exchange on the interlayer and on the basal plane surfaces [33]. So, in the experimental studies, the free $\mathrm{pH}$ value of 4.59 was chosen as the constant parameter. 


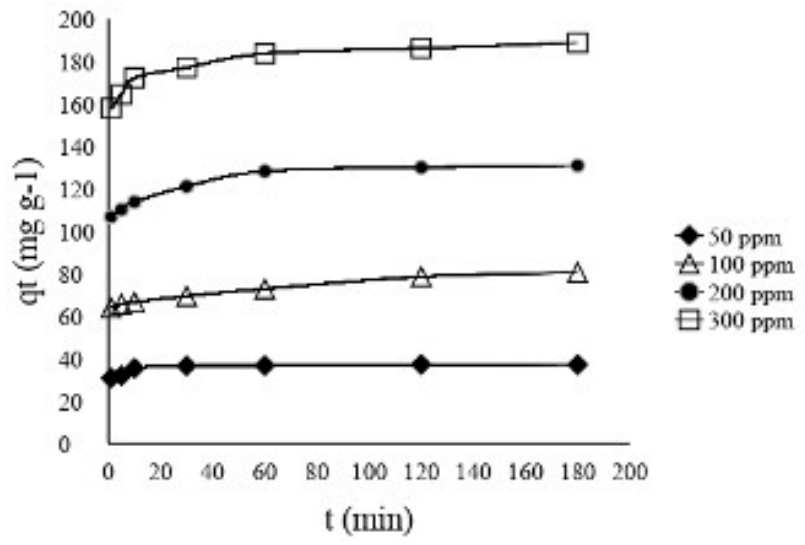

Fig.6. Determination of equilibrium time (free $\mathrm{pH} 4.59$, adsorbent mass $2.0 \mathrm{~g} / \mathrm{L}$, temperature $25^{\circ} \mathrm{C}$, strring speed $225 \mathrm{rpm}, 50-300$ ppm BY28 concentrations)

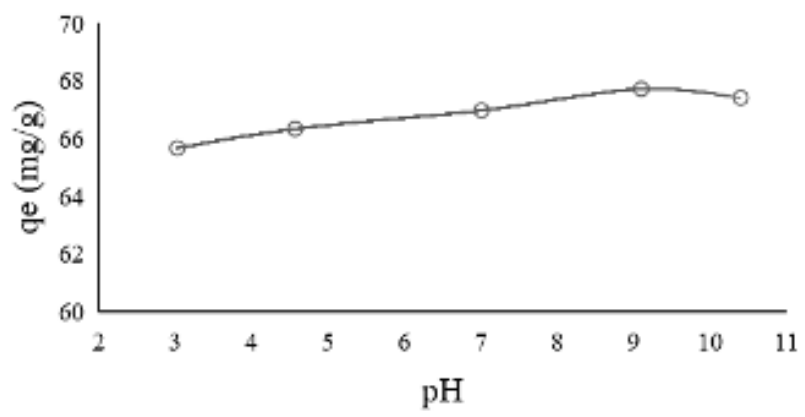

Fig. 7. Determination of suitable $\mathrm{pH}$ (contact time $60 \mathrm{~min}$, adsorbent mass $2.0 \mathrm{~g} / \mathrm{L}$, temperature $25^{\circ} \mathrm{C}$, strring speed $225 \mathrm{rpm}, 200$ ppm BY28 concentrations)

\subsection{NRC mass Effect}

The NRC mass effect was examined by changing from 0.5 to $10.0 \mathrm{~g} / \mathrm{L}$ and was given in Fig.8. As presented in Fig. 8. It could be clearly seen that the adsorption capacity $\left(\mathrm{q}_{\mathrm{e}}\right)$ decreases and adsorption percent increases with increasing in the NRC mass from 0.5 to $10.0 \mathrm{~g} / \mathrm{L}$. Regardless of the total NRC mass; As the surface area decreases, increasing the amount of adsorbent in a habituated volume decreases the number of available sites even if the number of adsorption sites per unit adsorbent mass remains constant [34].

The increased efficiency of removal results from the increase in adsorbent mass indicating more favorable adsorption sites and larger adsorption surface ${ }^{[35] .}$

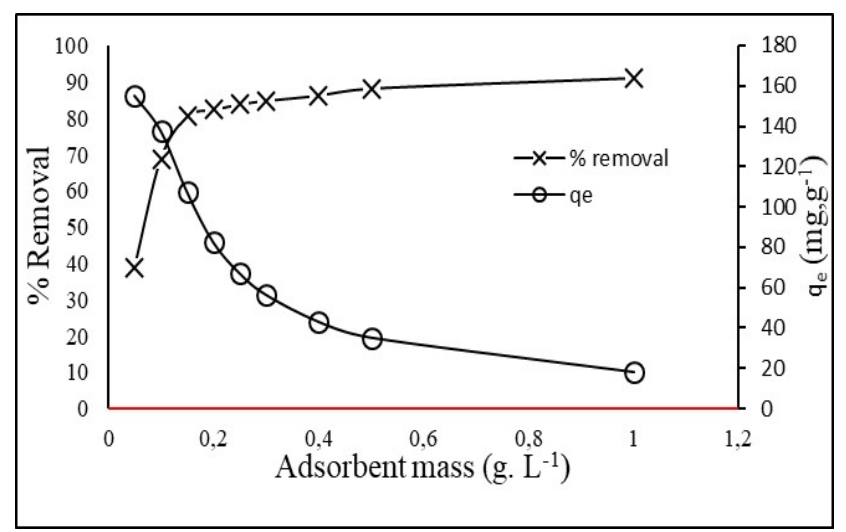

Fig. 8. Effect of adsorbent mass (contact time $60 \mathrm{~min}$, free $\mathrm{pH} 4.59$, temperature $25^{\circ} \mathrm{C}$, strring speed $225 \mathrm{rpm}, 200$ ppm BY28 concentrations)

\subsection{Temperature effect}

The temperature effect on the removal efficiency of the BY28 by $\mathrm{NRC}$ was examined at $25,30,35$ and $40^{\circ} \mathrm{C}$ (Fig.9.). The results of this figure show that the adsorption capacity $\left(\mathrm{q}_{\mathrm{e}}\right)$ increased by increasing the temperature from 25 to $40^{\circ} \mathrm{C}$. A similar behavior was observed in a study by Karagozoglu et al. [36]. With increasing in temperature, the diffusion rate between the NRC particles and the dye molecules increased [37]. This situation explains that the adsorption of BY28 at elevated temperatures is faster than at low temperatures due to the mobility of the BY28 molecules that increase with temperature increase [38].

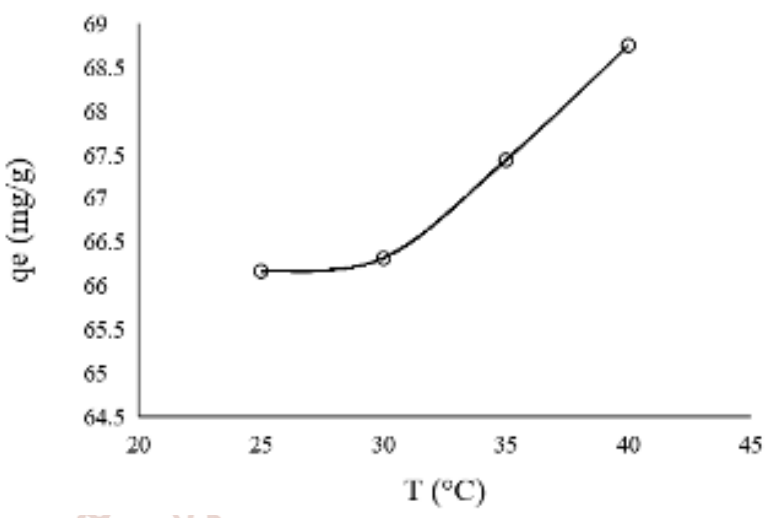

Fig. 9. Effect of adsorbent mass (contact time $60 \mathrm{~min}$, free $\mathrm{pH} 4.59$, temperature $25^{\circ} \mathrm{C}$, strring speed $225 \mathrm{rpm}, 200$ ppm BY28 concentrations)

\subsection{Analysis of the adsorption kinetics}

Four well-known kinetic models presented in Table $7 \mathrm{a}-\mathrm{b}$ were appropriated to investigate the adsorption process mechanism in the removal of BY28 from aqueous solution by using NRC as adsorbent. From Eq.7, when $\log \left(q_{\theta}-q_{t}\right)$ versus t is plotted (Fig.10), values of $\mathrm{k}_{1}$ and $\mathrm{q}_{\mathrm{e}}$ can be founded from the intercept and slope of linear relation. The kinetic constants in Eq.8-10 can be calculated in the same way. The $\mathrm{R}^{2}$ and kinetic constants for the kinetic models are listed in Table $7 \mathrm{a}-\mathrm{b}$.

When Table 7 a-b and Fig.10 is examined, the two kinetic models corresponding to the experimental data are Pseudo First Order and Pseudo Second Order models. $\mathrm{R}^{2}$ value of the Pseudo First Order kinetic model is approximately high. Nonetheless, the founded adsorption capacity from the Pseudo First Order kinetic model don't appropriate with the experimental results. This result displays that the BY28 adsorption onto the NRC may not be fit to the Pseudo First Order kinetic model. $\mathrm{R}^{2}$ values of the Pseudo Second Order kinetic model are greater than 0.993 and the values determined with accounts were found to be in considarable agreement values determined with experiments, which shows that the BY28 adsorption onto the NRC may be fit to the Pseudo Second Order kinetic model. Similar kinetic results were reported in the removal of BY28 from aqueous solution by using montmorillonite as adsorbent [39]. 


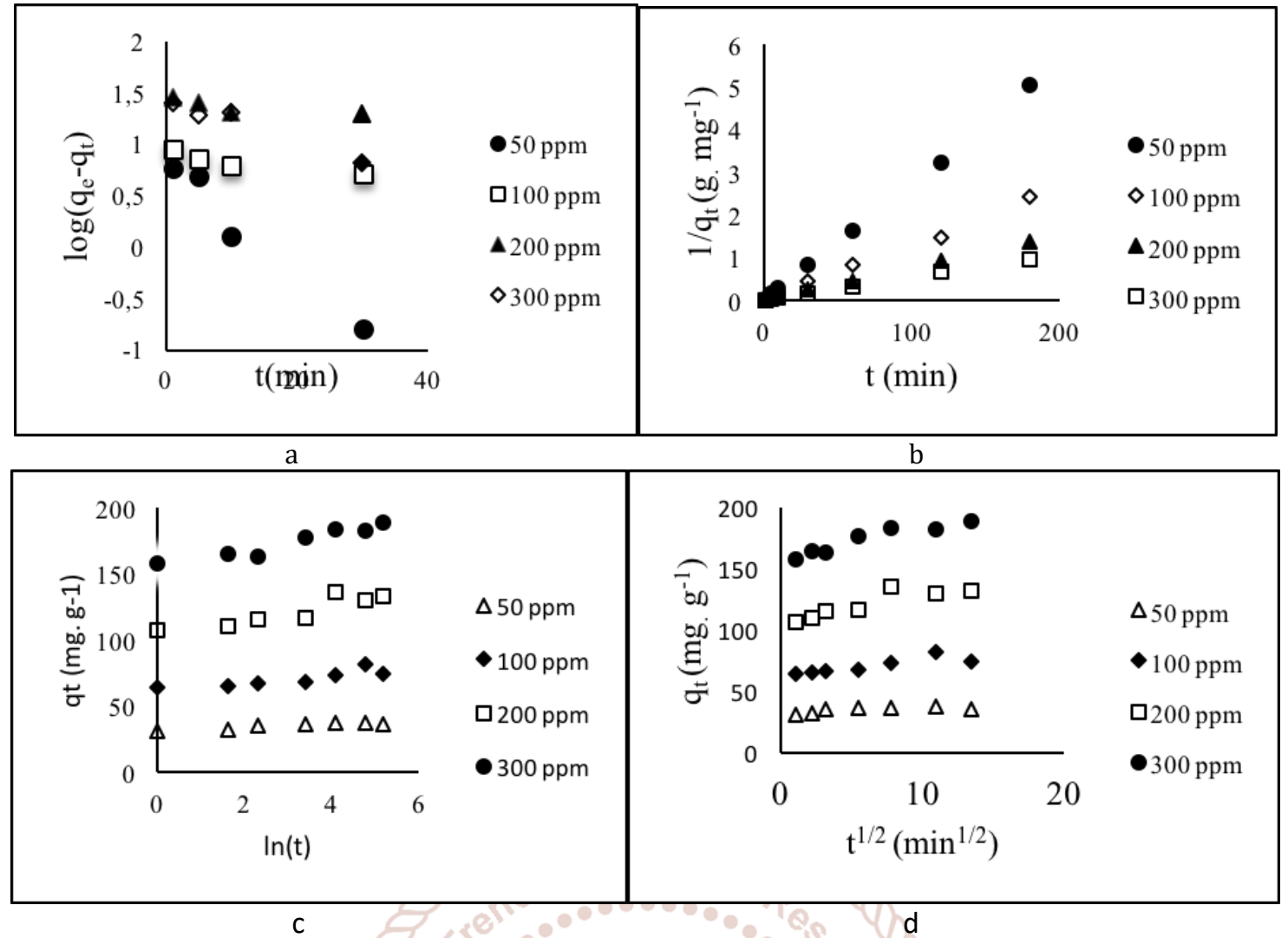

Fig.10. Kinetics curves for different kinetics models ( $a$-Pseudo First Order, b - Pseudo Second Order, c -Elovich, d Intraparticle diffusion,) (adsorbent mass $0.2 \mathrm{~g} / \mathrm{L}$, free $\mathrm{pH} 4.59$, temperature 25 , strring speed $225 \mathrm{rpm}$ )

Table 7 Comparison of the kinetic models for BY28 concentrations of at $25^{\circ} \mathrm{C}$.

\begin{tabular}{|c|c|c|c|c|c|c|c|c|}
\hline \multicolumn{3}{|c|}{ a } & \multicolumn{3}{|c|}{ Pseudo First Order } & \multicolumn{3}{|c|}{ Pseudo Second Order } \\
\hline Dye & $\begin{array}{c}\mathrm{C}_{0} \\
\left(\mathrm{mg} \mathrm{L}^{-1}\right) \\
\end{array}$ & $\begin{array}{c}q_{e, \exp } \\
\left(m g g^{-1}\right)\end{array}$ & $\begin{array}{c}k_{1} \\
\left(\min ^{-1}\right) \\
\end{array}$ & $\begin{array}{c}q_{\mathrm{e}, \mathrm{cal}} \\
\left(\mathrm{mg}_{\mathrm{g}} \mathrm{g}^{-1}\right) \\
\end{array}$ & $\mathbf{R}^{2}$ & $\begin{array}{c}\mathrm{k}_{2} \\
\left(\mathrm{~g} \cdot \mathrm{mg}^{-1} \cdot \mathrm{min}^{-1}\right)\end{array}$ & $\begin{array}{c}q_{\mathrm{e}, \mathrm{cal}} \\
\left(\mathrm{mg}_{\mathrm{g}} \mathrm{g}^{-1}\right)\end{array}$ & $\mathbf{R}^{2}$ \\
\hline \multirow{4}{*}{$\begin{array}{l}\text { BY } \\
28\end{array}$} & 50 & 36.81 & 0.127 & 6.683 & 0.969 & 0.058 & 37.175 & 0.999 \\
\hline & 100 & 72.86 & 0.0164 & 8.162 & 0.837 & 0.017 & 72.992 & 0.998 \\
\hline & 200 & 135.96 & 0.0124 & 26.859 & 0.676 & 0.0045 & 135.135 & 0.993 \\
\hline & 300 & 183.70 & 0.046 & 27.422 & 0.953 & 0.0067 & 185.185 & 0.999 \\
\hline
\end{tabular}

\begin{tabular}{|c|c|c|c|c|c|c|c|c|}
\hline \multicolumn{3}{|c|}{ b } & \multicolumn{3}{|c|}{ Elovich } & \multicolumn{3}{|c|}{ Intraparticle Diffusion } \\
\hline Dye & $\begin{array}{c}\mathrm{C}_{0} \\
\left(\mathrm{mg} \mathrm{L}^{-1}\right)\end{array}$ & $\begin{array}{c}q_{e, \exp } \\
\left(m g^{-1}\right)\end{array}$ & $\frac{\alpha}{\left(g^{\prime} m g^{-1}\right)}$ & $\frac{B}{\left(\mathrm{mgg}^{-1} \cdot \mathrm{dk}^{-1}\right)}$ & $\mathbf{R}^{2}$ & $\begin{array}{c}\mathrm{k}_{\text {Dif }} \\
\left(\mathrm{mgg}^{-1} \cdot \mathrm{min}^{-1 / 2}\right)\end{array}$ & C & $\mathbf{R}^{2}$ \\
\hline \multirow{4}{*}{$\begin{array}{l}\text { BY } \\
28\end{array}$} & 50 & 36.81 & $4.4 \mathrm{E}+11$ & 0.849 & 0.762 & 0.383 & 32.59 & 0.501 \\
\hline & 100 & 72.86 & 5724065887 & 0.347 & 0.711 & 1.188 & 62.977 & 0.756 \\
\hline & 200 & 135.96 & 501878150.5 & 0.176 & 0.825 & 2.216 & 107.25 & 0.785 \\
\hline & 300 & 183.70 & $4.4 \mathrm{E}+11$ & 0.161 & 0.922 & 2.433 & 158.66 & 0.885 \\
\hline
\end{tabular}

\subsection{Analysis of the adsorption isotherms}

Four well-known isotherm models presented in Table 4 were appropriated to investigate the the adsorption process mechanism in the removal of BY28 from aqueous solution by using NRC as adsorbent. From Eq. 3, when the plot Ce versus $\mathrm{Ce} / \mathrm{qe}$ is plotted, the values of $\mathrm{q}_{\mathrm{m}}$ and $\mathrm{K}_{\mathrm{L}}$ were founded from the intercept and slope of linear relation. The other isotherm constants in Eq. 4-6 can be calculated in the same way. The $\mathrm{R}^{2}$ and isotherm constants for the kinetic models are given in Table 8 and Fig. 11. 
Table 8 Isotherm parameters and $\mathrm{R}^{2}$ values of equilibrium isotherm models for the BY28 adsorption onto NRC at $25{ }^{\circ} \mathrm{C}$.

\begin{tabular}{|c|c|}
\hline Parameters of isotherm & BY28 \\
\hline \multicolumn{2}{|l|}{ Langmuir } \\
\hline $\mathrm{q}_{\mathrm{m}}\left(\mathrm{mg} \cdot \mathrm{g}^{-1}\right)$ & 370.4 \\
\hline $\mathrm{K}_{\mathrm{L}}\left(\mathrm{L} \cdot \mathrm{mg}^{-1}\right)$ & 0.0093 \\
\hline $\mathrm{R}_{\mathrm{L}}$ & 0.683 \\
\hline $\mathrm{R}^{2}$ & 0.994 \\
\hline \multicolumn{2}{|l|}{ Freundlich } \\
\hline $\mathrm{K}_{\mathrm{f}}\left[(\mathrm{mg} \cdot \mathrm{g}-1)\left(\left(\mathrm{L} \cdot \mathrm{mg}^{-1}\right)^{-1 / n}\right]\right.$ & 6.0757 \\
\hline $\mathrm{n}$ & 1.346 \\
\hline $\mathrm{R}^{2}$ & 0.990 \\
\hline \multicolumn{2}{|l|}{ Temkin } \\
\hline $\mathrm{K}_{\mathrm{T}}\left(\mathrm{L} . \mathrm{mg}^{-1}\right)$ & 0.14 \\
\hline $\mathrm{B}_{\mathrm{T}}$ & 68.06 \\
\hline $\mathrm{R}^{2}$ & 0.988 \\
\hline \multicolumn{2}{|l|}{ Dubinin-Radushkevich } \\
\hline$\beta_{\mathrm{DR}}\left(\times 10^{-6} \mathrm{~mol}^{2} \cdot \mathrm{kj}^{-2}\right)$ & 3.2 \\
\hline $\mathrm{q}_{\mathrm{m}}\left(\mathrm{mg} \cdot \mathrm{g}^{-1}\right)$ & 146.34 \\
\hline $\mathrm{R}^{2}$ & 0.717 \\
\hline
\end{tabular}

The experimental isotherm model obtained were compared with the models given in Table 8 and Fig. 11 . The values of Freundlich, Langmuir, Dubinin- Radushkevich and Temkin constants and $\mathrm{R}^{2}$ obtained by the statistical analysis. If $\mathrm{R}_{\mathrm{L}}$ value is in the range of $0-1, N R C$ is a suitable adsorbent for BY28 adsorption. At the same time, if $\mathrm{n}$ value is greater than $1, \mathrm{NRC}$ may be said to be a suitable adsorbent for BY28 adsorption. From the Table 10 and Fig. 11 ., at $25^{\circ} \mathrm{C}$, the isotherm model best suited to the adsorption of BY28 on NRC was found to be Langmuir with R2 value of 0.994 . Similar results were reported in the literature [40-44].

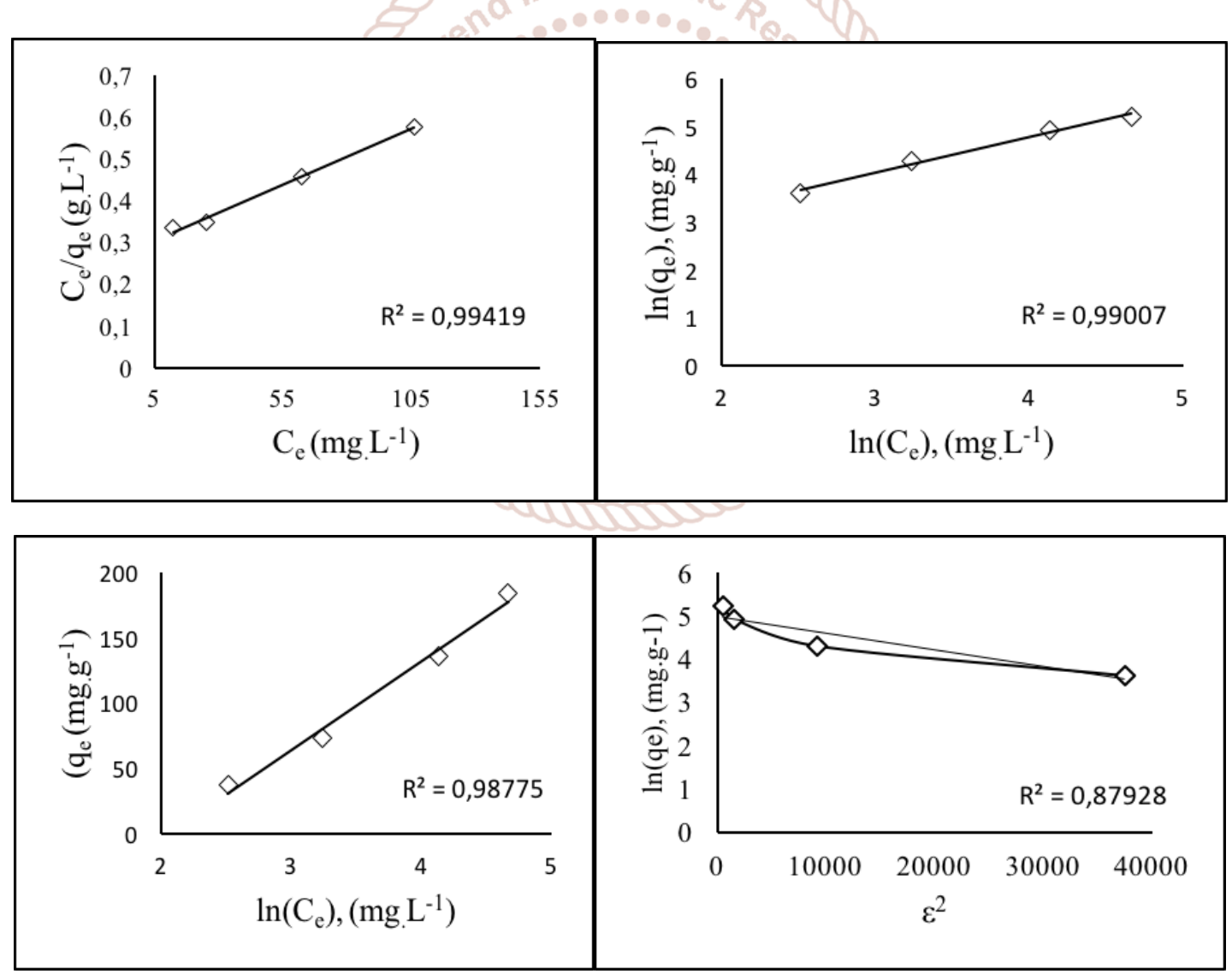

Fig.11. Isotherm curves for different isotherms models (a - Langmuir, b - Freundlich, c - Temkin, d - DubininRadushkevich,) (contact time: $60 \mathrm{~min}, \mathrm{pH}: 4.57$, dose of adsorbent: $0.2 \mathrm{~g}$, temperature: $25^{\circ} \mathrm{C}$ ).

\subsection{Adsorption thermodynamics}

From Eq. 13, when the plot 1/T versus ln Kc is plotted (Fig. 12), the values of $\Delta \mathrm{H}^{0}$ and $\Delta \mathrm{S}^{0}$ were founded from the intercept and slope of linear relation and then used to calculate $\Delta \mathrm{G}^{0}$ according to Eq. 11 . The thermodynamically parameters are presented in Table 9. 
International Journal of Trend in Scientific Research and Development (IJTSRD) @ www.ijtsrd.com eISSN: 2456-6470

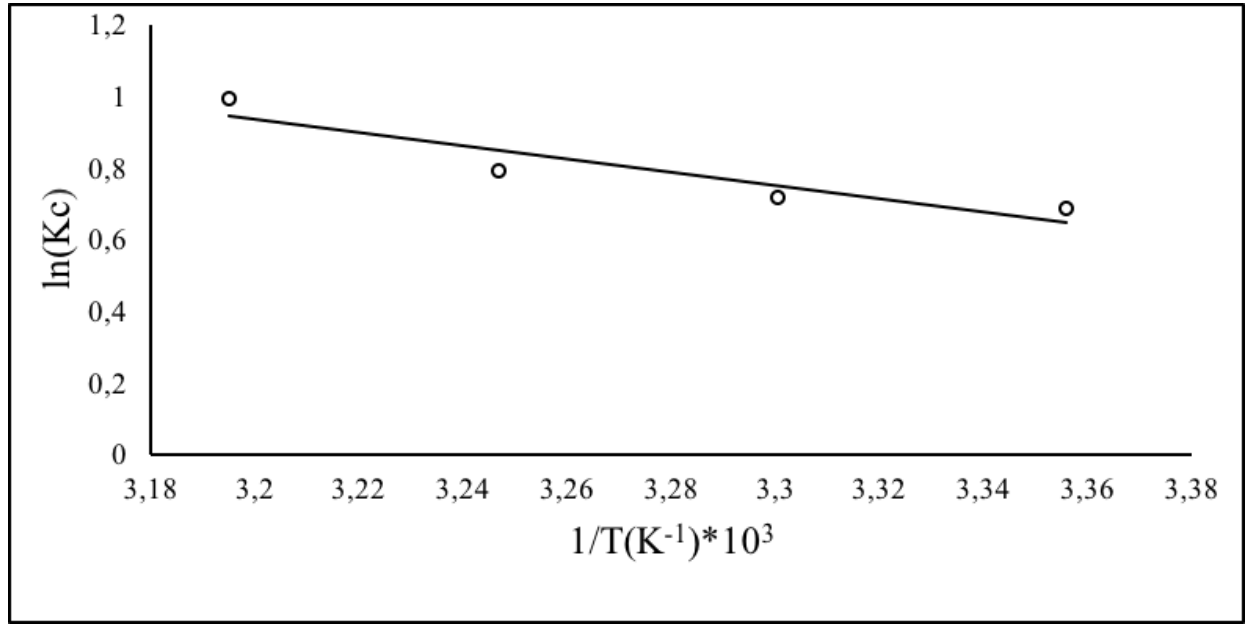

Fig.12. The plot ln Kc versus $1 / \mathrm{T}$

Table 9 Thermodynamic results in the adsorption of BY28 onto the NRC.

\begin{tabular}{|c|c|c|c|c|c|}
\hline$\Delta H^{\circ}\left(\mathrm{kJ} \cdot \mathrm{mol}^{-1}\right)$ & $\Delta S^{\circ}\left(\mathrm{J}_{\mathrm{mol}}^{-1}\right)$ & \multicolumn{4}{|c|}{$\Delta G^{\circ}\left(\mathrm{kJ} \cdot \mathrm{mol}^{-1}\right)$} \\
\hline $25^{0} \mathrm{C}$ & & $25^{0} \mathrm{C}$ & $30^{0} \mathrm{C}$ & $35^{0} \mathrm{C}$ & $40^{0} \mathrm{C}$ \\
\hline 15.4 & 57 & -1.6 & -1.9 & -2.2 & -2.5 \\
\hline
\end{tabular}

It can be verified by the positive values of the change of $\Delta \mathrm{H}^{0}$ (15.4 kJ.mol-1 for NRC) that the adsorption process of BY28 onto NRC is endothermic. The hydration phenomenon of dyestuff in water clarifies the endothermic of the BY28 adsorption. To ensure that BY28 ions to reach the adsorption sites and travel through the solution, the BY28 should first be peeled out of from the hydration shell, which requires energy input. If the attractive force generated by the adsorption of BY28 onto the NRC doesn't exceed the dehydration energy of the BY28 ions, the overall energy balance will lead to endothermic behavior [45].

On the basis of $\Delta \mathrm{H}^{0}$ value whether the physical adsorption $\left(20<\mathrm{kJ} \cdot \mathrm{mol}^{-1}\right)$ or the chemical adsorption $\left(80-200 \mathrm{~kJ} \cdot \mathrm{mol}^{-1}\right)$ takes place in the reaction can be inferred because $\Delta \mathrm{H}^{0}$ is associated to the different coactions that are setted between adsorbent and the adsorbed dye [46]. According to the presented results, the adsorption process of BY28 onto the NRC can be said to be carried out by physical adsorption because the value of $\Delta \mathrm{H}^{0}$ is lower than $20 \mathrm{~kJ} \cdot \mathrm{mol}^{-1}$.

The positive value of $\Delta \mathrm{S}^{0}$ values (57 $\mathrm{J}^{\mathrm{mol}}{ }^{-1}$ ) for NRC adsorbent shows that the haphazardness at the solid - liquid interface during the BY28 adsorption molecules onto the active sites of the NRC surface is increased. It also proposes great attention of BY28 towards the adsorbent.

The $\Delta \mathrm{G}^{0}$-negative values for the BY28 that are negative through the completely tested temperature range - confirms that the adsorption of dyes onto BY28 are favorable and spontaneous processes at all the experimental temperature. The values of $\Delta \mathrm{G}^{0}$ for BY28 became more negative with the increase of temperature, which suggested that the equilibrium capacity was increased. $\Delta \mathrm{G}^{0}$ for physical adsorption is between -20 and $0 \mathrm{~kJ} \cdot \mathrm{mol}^{-1}$ and for chemical adsorption is between -80 to $-400 \mathrm{~kJ} \cdot \mathrm{mol}^{-1}$ [47]. The adsorption of BY28 onto NRC was found to be carried out by physical adsorption, since the values of $\Delta \mathrm{H}^{0}$ and $\Delta \mathrm{G}^{0}$ for BY28 were in the range of physical adsorption in this study.
3.9. NRC comparison with other low cost adsorbents Even if adsorption studies are carried out on the same dye with different adsorbents, it is very difficult to make a comparison due to the different experimental conditions. So, the comparison was made only for the maximal monolayer adsorption capacity. For adsorption BY28 of onto low cost adsorbents, a comparison of the maximal monolayer adsorption capacities values founded in this study and earlier reported in the literature is given in Table 10. When this table is examined, the value obtained from this study is higher than the other works except one. According to this result, NRC adsorbent can be used successfully in the removal of BY28.

Table 10 The Comparison of the adsorption capacities obtained from studies to remove BY28

\begin{tabular}{|c|c|c|c|}
\hline Adsorbent & Isotherm & $\begin{array}{c}\mathrm{q}_{\mathrm{m}} \\
\left(\mathrm{mg}_{\mathrm{g}} \mathrm{g}^{-1}\right)\end{array}$ & Ref. \\
\hline Granula clay & Langmuir & $100-780$ & [48] \\
\hline NRC & Langmuir & 370 & $\begin{array}{l}\text { Present } \\
\text { study }\end{array}$ \\
\hline Bentonite & Langmuir & 256.4 & [33] \\
\hline $\begin{array}{l}\text { Aluminium-Pillared } \\
\text { Montmorillonite }\end{array}$ & - & 135 & [49] \\
\hline PMAA & Langmuir & 102 & {$[50]$} \\
\hline Ca-Bentonite & Langmuir & 94.3 & [38] \\
\hline $\begin{array}{l}\text { Boron Industry } \\
\text { Waste }\end{array}$ & Generalized & 75 & [51] \\
\hline Clinoptilolite & Langmuir & 59.6 & [5] \\
\hline Green Macroalga & Langmuir & 35.5 & [52] \\
\hline Green Alga & Freundlich & 27 & [53] \\
\hline Persian Kaolin & Langmuir & 16.2 & [54] \\
\hline Amberlite XAD-4 & Langmuir & 14.9 & [5] \\
\hline
\end{tabular}

\section{CONCLUSIONS}

NRC has been used as an adsorbent with low cost for removal of cationic dyes BY28 from the aqueous solution. Adsorption equilibrium time was found as $60 \mathrm{~min}$. The $\mathrm{pH}$ value of the NRC was chosen as 4.59 , which is the free $\mathrm{pH}$ value of NRC in aqueous solutions, since the $\mathrm{pH}$ effect on the dye removal efficiency is not significant. $\mathrm{R}^{2}$ values of the Pseudo Second Order kinetic model are greater than 0.993 
and the values of calculated were found to be in considarable agreement with the experimental values, which shows that the BY28 adsorption onto the NRC may be fit to the Pseudo Second Order kinetic model. The isotherm model best suited to the adsorption of BY28 on NRC is found to be Langmuir with R2 value of 0.994 . The max. monolayer adsorption capacity was $370 \mathrm{mg}^{-1} \mathrm{~g}^{-1}$. The positive values of $\Delta \mathrm{H}^{0}(15.4$ kJ.mol-1 for NRC) confirm that adsorption processes of BY28 onto NRC is endothermic. The adsorption of BY28 onto NRC are favorable and spontaneous processes at all the experimental temperature, since the negative values of $\Delta \mathrm{G}^{0}$ for the BY28 were negative. The adsorption of BY28 onto NRC was said to be carried out by physical adsorption, since the values of $\Delta \mathrm{H}^{0}$ and $\Delta \mathrm{G}^{0}$ for BY28 were in the range of physical adsorption in this study. Finally, NRC can be effectively used for the removal of cationic dyes since it is a low cost and abundant adsorbent.

\section{References}

[1] C. Galindo, P. Jacques and A. Kalt, Photooxidation of the phenylazonaphthol A020 on TiO2: kinetic and mechanistic investigations, Chemosphere 45 (2001) 997-1005.

[2] V.J.P. Poots, G. McKay, J.J. Healy, Removal of Basic Dye from Effluent Using Wood as an Adsorbent, J. WPCF (1978) 926-935.

[3] Apurva A. Narvekar, J. B. Fernandes and S. G. Tilve, Adsorption behavior of methylene blue on glycerol based carbon materials, J. Environ. Chem. Eng, 6.2 (2018) 1714-1725.

[4] A. Al-Futaisi, A. Jamrah and R. Al-Hanai, Aspects of cationic dye molecule adsorption to palygorskite, Desalination 214 (2007) 327-342.

[5] J. Yener, T. Kopac, G. Dogu and T. Dogu, Batch adsorber rate analysis of Methylene Blue on Amberlite and Clinoptilolite, J. Colloid Interf. Sci. 294 (2006) 255-264.

[6] FigenGündüz, BaharBayrak, Biosorption of malachite green from an aqueous solution using pomegranate peel: Equilibrium modelling, kinetic and thermodynamic studies, J. Mol. Liq., 243 (2017) 790798.

[7] S. J. Allen, G. McKay and J.F. Porter, Adsorption isotherm models for basic dye adsorption by peat in single and binary component systems, J. Colloid Interf. Sci. 280 (2004) 322-333.

[8] H. Aydin and G. Baysal, Adsorption of acid dyes in aqueous solutions by shells of bittim (pistacia khinjuk stocks), Desalination 196 (2006) 248-259.

[9] AYW. Sham and MN. Shannon, Adsorption of organic dyes from aqueous solutions using surfactant exfoliated graphene, J. Environ. Chem. Eng, 6.1 (2018) 495-504.

[10] G. Annadurai, R. S. Juang and D.J. Lee, Use of cellulosebased wastes for adsorption of dyes from aqueous solutions, J. Hazard. Mater. 92 (2002) 263-274.

[11] Khadra-Hanane Toumi, Manel Bergaoui, Mohamed Khalfaoui, Yacine Benguerba, Alessandro Erto,Guilherme L. Dotto, Abdeltif Amrane, Saci Nacef, Barbara Ernst, Computational study of acid blue 80 dye adsorption on low cost agricultural Algerian olive cake waste: Statistical mechanics and molecular dynamic simulations, J. Mol. Liq., 271 (2018) 40-50.

[12] Abida Kausar, Munawar Iqbal, Anum Javed, Kiran Aftab, Zill-i-Huma Nazli, Haq Nawaz Bhatti, Shazia Nouren,
Dyes adsorption using clay and modified clay: A review, J. Mol. Liq., 256 (2018) 395-407.

[13] Duan Xin-hui, C. Srinivasakannan, Wen-Wen Qu, Wang Xin, Peng Jin-hui, Zhang Li-bo, Regeneration of microwave assisted spent activated carbon: Process optimization, adsorption isotherms and kinetics, Chem. Eng. Process. 53 (2012) 53-62.

[14] M. Ugurlu, A. Gürses, M. Açıkyıldız, Comparison of textile dyeing effluent adsorption on commercial activated carbon and activated carbon prepared from olive stone by $\mathrm{ZnCl} 2$ activation, Micropor. Mesopor. Mater. 111 (2008) 228-235.

[15] L. Wang, J. Zhang, R. Zhao, C. Li, Y. Li, C. Zhang, Adsorption of basic dyes on activated carbon prepared from Polygonum orientale Linn.: equilibrium, kinetic and thermodynamic studies, Desalination 254 (2010) 68-74.

[16] R. Darvishi Cheshmeh Soltani, A.R. Khataee, M. Safari, S.W. Joo, Preparation of bio-silica/chitosan nanocomposite for adsorption of a textile dye in aqueous solutions, Int. Biodeter. Biodegr. 85 (2013) 383-391.

[17] M. Kıranşan, R. Darvishi Cheshmeh Soltani, A. Hassani, S. Karaca, A. Khataee, Preparation of cetyltrimethylammonium bromide modified montmorillonite nanomaterial for adsorption of a textile dye, J. Taiwan Inst. Chem. Eng. 45 (2014) 25652577.

[18] Y. Park, G.A. Ayoko, R.L. Frost, Application of organoclays for the adsorption of recalcitrant organic molecules from aqueous media, J. Colloid Interface Sci. 354 (2011) 292-305.

[19] S. Arellano-Cárdenas, S. López-Cortez, M. CornejoMazón, J.C. Mares-Gutiér- rez, Study of malachite green adsorption by organically modified clay using a batch method, Appl. Surf. Sci. 280 (2013) 74-78.

[20] R. Darvishi Cheshmeh Soltani, A.R. Khataee, H. Godini, M. Safari, M.J. Gha-nadzadeh, M.S. Rajaei, Response surface methodological evaluation of the adsorption of textile dye onto biosilica/alginate nanobiocomposite: thermodynamic, kinetic, and isotherm studies, Desalin. Water Treat. (2014) 1-14.

[21] Akbulut, S., Gürses, A., Arasan, S., Korucu, M. ve Kurt, Z.N. Kil Tanelerin (Nanokil) Kristal Yapılarının Poliorganiklerle Desteklenerek Killerin Hidrolik İletkenlik Ve Mukavemet Özelliklerinin İyileştirilmesi, Tübitak, Proje No: 107Y295, 2011. (in Turkish).

[22] I. Langmuir, The adsorption of gases on plane surfaces of glass, mica and platinum, JACS. 40 (1918) 13611403.

[23] H. Freundlich, Over the adsorption in solution, J. Phys. Chem. 57 (1906) 1100-1107.

[24] M.I. Temkin, Adsorption equilibrium and the kinetics of processes on nonhomogeneous surfaces and in the interaction between adsorbed molecules. Zh. Fiz. Chim. 15 (1941) 296-332.

[25] MM. Dubinin, The equation of the characteristic curve of activated charcoal vol. 55, InDokl. Akad. Nauk. SSSR. (1947), 327-329.

[26] Chaari Islem, Cherbib Afef, Fakher jamaussi, Medhioub Mounir and Mnif Adel, Adsorptive/Desorptive Potential of Cationic Basic Yellow 28 (BY28) Dye onto Natural 
Untreated Clay from Aqueous Phase, OAJS. (2018),vol. 2(1),1-6.

[27] McKay, G., Y. S. Ho, and J. C. Y. Ng. Biosorption of copper from wastewaters: a review. Separ. Purif. Methods. 28 (1999) 87-125.

[28] Moore, Duane Milton, and Robert C. Reynolds. X-ray Diffraction and the Identification and Analysis of Clay Minerals. Second edition, New York: Oxford University press, 1997.

[29] Biscaye, Pierre E. Mineralogy and sedimentation of recent deep-sea clay in the Atlantic Ocean and adjacent seas and oceans. Geol. Soc. Am. Bull. 76 (1965) 803832.

[30] B.H. Hameed, Equilibrium and kinetic studies of methyl violet sorption by agricultural waste, J. Hazard. Mater. 154 (2008) 204-212.

[31] B.H. Hameed, M.I. El-Khaiary, Removal of basic dye from aqueous medium using a novel agricultural waste material: Pumpkin seed hull, J. Hazard. Mater. 155 (2008) 601-609.

[32] E. Eren, B. Afsin, Investigation of a basic dye adsorption from aqueous solution onto raw and pre-treated bentonite surfaces, Dyes Pigm. 76 (2008) 220-225.

[33] M. Turabik, Adsorption of basic dyes from single and binary component systems onto bentonite: simultaneous analysis of basic red 46 and basic yellow 28 by first order derivative spectrophotometric analysis method, J. Hazard. Mater. 158 (2008) 52-64.

[34] Jiao, Xuan, Lingyan Zhang, Yangshuai Qiu, and Yunru Yuan. A new adsorbent of $\mathrm{Pb}$ (II) ions from aqueous solution synthesized by mechanochemical preparation of sulfonated expanded graphite. RSC Adv. Issue:61 (2017) 38350-38359.

[35] Garg, Vinod K., Moirangthem Amita, Rakesh Kumar, and Renuka Gupta. Basic dye (methylene blue) removal from simulated wastewater by adsorption using Indian Rosewood sawdust: a timber industry waste. Dyes and pigm. 63 (2004) 243-250.

[36] Karagozoglu, B., M. Tasdemir, E. Demirbas, and M. Kobya. The adsorption of basic dye (Astrazon Blue FGRL) from aqueous solutions onto sepiolite, fly ash and apricot shell activated carbon: kinetic and equilibrium studies. J. Hazard. Mater. 147 (2007) 297306.

[37] Salleh, Mohamad Amran Mohd, Dalia Khalid Mahmoud, Wan Azlina Wan Abdul Karim, and Azni Idris. Cationic and anionic dye adsorption by agricultural solid wastes: A comprehensive review. Desalination. 280 (2011) 1-13.

[38] Kalpakll, Yasemen, Şafak Toygun, Gülhan Köneçoğlu, and Mesut Akgün. Equilibrium and kinetic study on the adsorption of basic dye (BY28) onto raw Cabentonite. Desalin. Water Treat. 52 (2014) 7389-7399.

[39] Sozudogru, Onur, Baybars Ali Fil, Recep Boncukcuoglu, Erdinç Aladag, and Sinan Kul. Adsorptive removal of cationic (BY2) dye from aqueous solutions onto Turkish clay: Isotherm, kinetic, and thermodynamic analysis. Part. Sci. Technol. 34 (2016) 103-111.

[40] G.K. Ramesha, A.V. Kumara, H.B. Muralidhara, S. Sampath, Graphene and graphene oxide as effective adsorbents toward anionic and cationic dyes, J. Colloid Interf. Sci. 361 (2011) 270-277.

[41] W. Zhang, C. Zhou, W. Zhou, A. Lei, Q. Zhang, Q. Wan, B. Zou, Fast and considerable adsorption of methylene blue dye onto graphene oxide, Bull. Environ. Contam. Toxicol. 87 (2011) 86-90.

[42] Y. Yao, S. Miao, S. Yu, L.P. Ma, H. Sun, S. Wang, Fabrication of Fe304/SiO2 core/shell nanoparticles attached to graphene oxide and its use as an adsorbent, J. Colloid Interf. Sci. 379 (2012) 20-26.

[43] L. Sun, H. Yu, B. Fugetsu, Graphene oxide adsorption enhanced by in situ reduction with sodium hydrosulfite to remove acridine orange from aqueous solution, J. Hazard. Mater. 203-204 (2012) 101-110.

[44] Y. Li, Q. Du, T. Liu, X. Peng, J. Wang, J. Sun, Y. Wang, S. Wu, Z. Wang, Y. Xia, L. Xia, Comparative study of methylene blue dye adsorption onto activated carbon, graphene oxide, and carbon nanotubes, Chem. Eng. Res. Des. 91 (2013) 361-368.

[45] M. Bahgat, A.A. Farghali, W. El Rouby, M. Khedr, M.Y. Mohassab-Ahmed, Adsorption of methyl green dye onto multi-walled carbon nanotubes decorated with $\mathrm{Ni}$ nanoferrite, Appl. Nanosci. 3 (2013) 251-261.

[46] D. Sun, Z. Zhang, M. Wang, Y. Wu, Adsorption of reactive dyes on activated carbon developed from enteromorpha prolifera, Am. J. Anal. Chem. 4 (2013) 17-26.

[47] Crini, Grégorio, and Pierre-Marie Badot, eds. Sorption processes and pollution: Conventional and nonconventional sorbents for pollutant removal from wastewaters. Presses Univ. Franche-Comté, 2010.

[48] B. Cheknane, O. Bouras, M. Baudu, J. Basly, A. Cherguielaine, Granular inorgano-organo pillared clays (GIOCs): preparation by wet granulation, characterization and application to the removal of a basic dye (BY28) from aqueous solutions, Chem. Eng. J. 158 (2010) 528-534.

[49] B. Cheknane, F. Zermane, M. Baudu, O. Bouras, J. Basly, Sorption of basic dyes onto granulated pillared clays: thermodynamic and kinetic studies, J. Colloid Interface Sci. 381 (2012) 158-163.

[50] V. Vesna, Panic, Zeljka P. Madzarevic, Tatjana VolkovHusovic, Sava J. Velickovic, Poly (methacrylic acid) based hydrogels as sorbents for removal of cationic dye basic yellow 28: Kinetics, equilibrium study and image analysis, Chem. Eng. J. 217 (2013) 192-204.

[51] A. Olgun, N. Atar, Equilibrium and kinetic adsorption study of basic yellow 28 and basic red 46 by a boron industry waste, J. Hazard. Mater. 161 (2009) 148-156.

[52] P. Pimol, M. Khanidtha, P. Prasert, Influence of particle size and salinity on adsorption of basic dyes by agricultural waste: dried Seagrape (Caulerpa lentillifera), J. Environ. Sci. 20 (2008) 760-768.

[53] R. Aravindhan, J. Rao, B. Nair, Removal of basic yellow dye from aquous solution by sorption on green alga Caulerpa scalpelliformis, J. Hazard. Mater. 142 (2007) 68-76.

[54] A. Tehrani-Bagha, H. Nikkar, N. Mahmoodi, M. Markazi, F. Menger, The sorption of cationic dyes onto kaolin: kinetic, isotherm and thermodynamic studies, Desalination 266 (2011) 274-280. 